moon and full moon, at the boundary plane appertaining to the moon. The result is that all parts of the mass are perpetually undergoing considerable cross-strains, for the forces of tension and compression will not relieve each other, as they act at right angles to one ano!her.

If the mass of the earth were not rigid, but sufficiently elastic, like, for instance, a globe of india-rubber, the particles would yield to their small disturbing forces; and the result would be that each particle, as it arrived by rotation at cach point of its circuit, would move in proportion to the force acting on it, one way or the other. In this case there would be nothing to cause the axis to move; the earth would steadily revolve, and no precession or nutation would occur. The whole mass would, as it were, breathe, heaving its surface and drawing it in again in a complicated undulation.

But observation shows that the earth has precession and nutation; and therefore the mass cannot be thus elastic.

If it be only partially rigid, then there would be a correspond. ing degree of yielding; but precession and nutation would still be produced, and a strain, in a somewhat diminished degree, affect the mass

Now, mathematical calculation made on the hypothesis of the earth's mass being ahsolutely rigid, and that throughout, shows that the annual precession would be $5 I^{\prime} 3566^{\prime \prime}$.* Astronomical observation shows that the precession is actually $50^{\prime} \mathrm{I}^{\prime \prime}$. The remarkable nearness of these results is sufficient proof that the earth's mass is not the limp thing some take it to be ; all viscous-fluid from only Ioo miles down to the centre, moving so slowly, that it gives inertia to the hard crust (supposed thin) as if it were all solid! It is more like the highly rigid mass which Sir William Thomson has shown it to be from other considerations.

Calcutta, July I 5

JOHN H. PRA'T

\section{Meteorology in South Australia}

As it may be interesting to some of your English readers to hear something of natural phenomena in such an out-of-the-way part of the world as South Australia, I forward a description of three very fine meteors which have lately been seen here, as well as a splendid display of Aurora Australis.

On January 5 th, 187 I, at about half-past nine P.M., I observed a splendid meteor. It appeared at first like a fixed star about three times as large as Jupiter, or say six or seven inches in diameter, and was probably about $15^{\circ}$ above the horizon, or nearly of the same apparent height as a large star which was just below the planet Jupiter, a little to the west of him and within half an hour of the meridian. The meteor, which was very brilliant, somewhat of the appearance of Jupiter, remained apparently stationary for, at least, five seconds; it then gradually began to move from a due north position to a direction about S.S.E., and in a horizonthl line it then burst into several smaller meteors and went out, having lasted fully twenty secnnds altogether. The moon was shining brightly at the time, being a few days off the full.

On the same night, and at about the same hour, a large meteor was seen by a survey party at Hookina, a place about 400 miles north of Adelaide. The surveyor in charge of the party (Mr. Hamilton) from whom I obtained the particulars of this meteor, says he was facing the east when he observed it going from N.E. to S. E., describing a large arc at an apparent elevation of $20^{\circ}$. $\mathrm{He}$ describes its colour as greenish, and so bright that it almost overpowered the light of the moon. It ulimately burst with a loud explosion into a number of fragments of red and blue colours, and the earth was felt to tremble as though a shock of an earthquake had occurred.

On the $25^{\text {th }}$ March last, at about twenty minutes to three o'clock in the afternoon, I observed a meteor in the full blaze of the sun. It appeared like a bright brass-coloured ball of fire, shooting through the sky like a rocket; it seemed to have a green and blue light round a central brass-coloured nucleus. The meteor appeared about three inches in diameter; it had a whitish comet-like tail, about three feet long, and it came from the N.N.E. and travelled downwards towards the S.S.W., so that as I was looking south it appeared to come over my left shoulder. It lasted about ten seconds, then burst without noise, and became dissipated. This meteor seemed to fall at about $15^{\circ}$ from the horizon.

In the S. A. "Register," a few days after seeing the last

* See this worked out in my "Mechanical Philosophy," rst edit. p. 562, and edit. p. $54^{\circ}$. described meteor, it was stated that a surprising sound was heard at Point Macleay, and other places about fifty or sixty miles to the south-east of Adelaide as of the firing of cannon, and the correspondent of that paper at Mannum (a place on the River Murray, about sixty miles east of Adelaide) writes as follows :-

"On Saturday last (25th March) at exactly 2.45 P.M., I was looking down the Murray River, when suddenly my attention was attracted by a large ball of fire falling from the heavens in almost a perpendicular course. The lakes are from here in the direction which it indicated-almost due south - so that I have no doubt the extraordinary phenomenon mentioned as having occurred on the shores of Lake Alexandrina, may have arisen from one of the causes assigned, viz., a falling meteor or an aerolite. What I saw was evidently the explosion immediately preceding the fall, and it presented the appearance of a luminous meteor." ...

The display of "aurora australis" which I observed on the 23rd March last, commenced at about eight o'clock P. M. It increased in brightness till eleven o'clock, when it gradually faded away. At about two o'clock A M., while at a ball, I came out on the balcony and observed the whole southern sky lighted up by a most gorgeous display of aurora. It occupied about $70^{\circ}$ or $80^{\circ}$ of the horizon, extending from about S.S.E to S.W, and reached to a height of say $60^{\circ}$ above the horizon. It was of a splendid red rose colour and streaked with beams of white light at various distances apart--say two bands of white in every $10^{\circ}$. These white bands appeared about two feet to five feet wide, which would answer to say $5^{\circ}$ observed by the eye alone. The display was so bright that by placing my hand with the fingers apart at about two feet from a lady's white dress, I could distinctly see the shadow of each finger. This aurora was also seen in Victoria and New South Wales.

I may mention that Adelaide is situated in south latitude about $35^{\circ}$, and longitude $138^{\circ} 40^{\prime}$

Adelaide, June 19

\section{The Solar Aurora Theory}

IN the very interesting lecture of Mr. Lockyer upon the recent solar eclipse which has just appeared in NATURE, he says, speaking of the green line layer above the hydrogen, "Here obviously we have, I think, merely an indication of another substance thinning out, in spite of the extraordinary suggestion which was put forward that the corona was nothing but a permanent solar aurora."

I agree entirely in this view except as to what would seem to be implied by the expression in spite of. I fail to see any inconsistency between the idea of a substance "thinning out" and a permanent solar aurora,

What $I$ intended in adopting and endorsing this auroral hypo. thesis was simply this : to express the belief (which I still hold, though with no great tenacity) that the substance which com. poses this green-line layer is also found in the upper regions of our atmosphere in a state of almost inconceivable tenuity, and at an elevation of certainly more than one hundred miles; and, further, that the peculiar filamentary and radiant structure of the corona, and very possibly its luminosity to some extent, are due to solar forces closely analogous to those which produce our terrestrial auroras.

Or in other words, that an observer, at the planet Mars for instance, looking at the earth during a period of auroral activity would see its poles capped by a corona in substance, structure, and to some extent in origin, closely analogous to that which is permanent around the sun.

And if we grant the identity of the 1474 line with that which is, to say the least, so closely coincident with it in the auroral spectrum, it is difficult to see why the hypothesis should be considered "extracrdinary," or per se improbable.

That the enormous chemical, thermal, Iuminous, and magnetic activity of the solar surface should be unaccompanied by manifestations of what we call electric energy seems far more unlikely than the contrary ; and if such energy operates we should naturally look for phenomena, the counterparts of those by which it shows itself here, but on the solar scale of course.

As to the identity of these lines, however, there may fairly remain some doubt. This line in the spectrum of the aurora is so rarely seen, so faint, and so difficult of observation, that, although the few observations thus far obtained show even a surprising agreement with each other and with this idea, it is safer to maintain a cautious reserve.

Dartmouth College, U.S.A., August 16
C. A. Young 